\title{
Interleukin-17 potently increases non-small cell lung cancer growth
}

\author{
LEI WEI, HUI WANG, FEN YANG, QI DING and JIANHUA ZHAO \\ Department of Anesthesiology, Suzhou Municipal Hospital Affiliated to Nanjing Medical University, \\ Suzhou, Jiangsu 215002, P.R. China
}

Received January 16, 2015; Accepted November 6, 2015

DOI: $10.3892 / \mathrm{mmr} .2015 .4694$

\begin{abstract}
The aim of the present study was to explore the effects of interleukin (IL)-17 on the growth and metastasis of tumors that were subcutaneously implanted into C57BL/6 mice. Lewis lung carcinoma (LLC) cells were subcutaneously injected into C57BL/6 mice followed by intraperitoneal injection of mouse recombinant IL-17 protein (IL-17 groups) or phosphate-buffered saline (control groups). Tumor growth and metastasis were assessed by measuring the size and weight of tumors and cervical lymph nodes, respectively. Cytokine expression in tumor masses was quantified by reverse transcription-quantitative polymerase chain reaction and western blotting, respectively. CCR2-positive macrophage infiltration in tumor masses was detected by flow cytometric analysis. The proliferation and migration of LLC cells, stimulated by the IL-17 protein were detected by Cell Counting kit (CCK)-8 and wound scratch assays in vitro. Tumors were grafted into the C57BL/6 mice. The mice that were intraperitoneally injected with IL-17 exhibited significantly larger tumors compared with the control mice. After day 7 of injection and beyond, the weight of cervical lymph nodes in IL-17 groups was higher than that in the control mice. It was also demonstrated that the number of CCR2-positive macrophages that infiltrated the tumor masses in the IL-17 groups was higher than that of the control mice. CD34 expression in vascular endothelial cells was also higher in tumors grafted in IL-17 mice than those grafted in control mice. Furthermore, the tumor tissue mRNA and protein expression levels of vascular endothelial growth factor, matrix metalloproteinase (MMP)-2, MMP-9 and tumor necrosis factor- $\alpha$ were greater in mice from the IL-17 group than the control mice, while levels of migration inhibitory factor and thrombospondin-1 were lower in mice from
\end{abstract}

Correspondence to: Mr. Jianhua Zhao, Department of Anesthesiology, Suzhou Municipal Hospital Affiliated to Nanjing Medical University, 26 Daoqian Street, Suzhou, Jiangsu 215002, P.R. China

E-mail: zjh1817@sina.com

Key words: lung cancer, interleukin-17, angiogenesis, metastasis, tumor growth the IL-17 group than in the control. IL-17 also increased the migration of LLC cells in vitro. In conclusion, IL-17 exhibited the ability to promote tumor growth by increasing angiogenesis, metastasis and increasing $\mathrm{CCR} 2^{+}$macrophage infiltration into tumors.

\section{Introduction}

Non-small-cell lung cancer (NSCLC) is one of the most common types of malignancy worldwide (1). With $>1,000,000$ novel cases per year, lung cancer represents the most frequent lethal neoplasm in males, while its incidence increases progressively in females (2). Despite considerable efforts, only 5-10\% of patients survive 5 years after diagnosis and the majority of these long-term survivors undergo surgery (3). Therefore, tumor angiogenesis and tumor metastasis to multiple organs is a critical problem for patients with lung cancer. The prevention and treatment of tumor angiogenesis and tumor metastasis is clinically important (4).

Interleukin (IL)-17 is produced predominantly by activated CD4 T cells (5). It has pleiotropic biological activities including induction of IL-6, CXCL8/IL-8 and vascular endothelial growth factor-A (VEGF-A) (5-14). IL-17R is a type 1 transmembrane protein with an extraordinarily long intracellular domain $(5,15)$. Although the expression of IL-17 mRNA is restricted to activated $\mathrm{T}$ cells, the expression of IL-17R mRNA has been detected in nearly all cells and tissues $(5,15)$. In its role as a proinflammatory cytokine, IL-17 levels have been found to significantly increase in rheumatoid arthritis synovium and in other chronic inflammatory diseases, including multiple sclerosis and psoriasis (16-20). IL-17 has also been implicated in certain tumors, affecting tumorigenesis, proliferation, angiogenesis and metastasis. This allows the tumor to adapt and to confer immune and chemotherapy resistance (21). Accumulating evidence has shown that IL-17-positive cells are frequently present in multiple inflammation-associated cancers and that IL-17 promotes angiogenesis in tumor models (22). Expression of IL-17 is correlated with the number of blood vessels in human ovarian cancer (23), hepatocellular carcinoma (24) and NSCLC (25), and with poor survival in hepatocellular carcinoma (24).

Although IL-17 is central in endothelial proliferation and tumor growth in several types of cancer (23), its possible 
effects on lung cancer and the precise mechanism underlying its biologic function remain unclear $(24,25)$. To further address the roles of IL-17 in lung cancer, Lewis lung carcinoma (LLC) cells were transplanted into C57BL/6 mice to examine the roles of IL-17 in the processes of tumorigenesis and metastasis in vivo. Tumor size, lymph node weight and angiogenic factors, which were expressed in tumor mass, as indicated at the time point following implantation were detected and compared. The present study provided definitive evidence of a critical role of IL-17 in LLC cell-implanted tumor growth and metastasis.

\section{Materials and methods}

Reagents and antibodies. Mouse recombinant protein IL-17 was purchased from Biochem Technologies (Shanghai, China). Rat anti-mouse CD34 monoclonal antibody (mAb) (MEC 14.7, cat no. NB600-1071), phycoerythrin (PE)-conjugated rat antimouse F4/80 mAb (cat no. NBP2-22134), rat anti-mouse vascular endothelial growth factor (VEGF) mAb (RM0009-2G02, cat no. NB110-61025), rabbit anti-mouse matrix metalloproteinase (MMP)2 mAb (cat no. NB200-193), rabbit anti-mouse MMP9 mAb (cat no. NBP1-39597), rabbit anti-mouse tumor necrosis factor (TNF)- $\alpha$ mAb (cat no. NB100-57620) and mouse antimouse glyceraldehyde 3-phosphate dehydrogenase (GAPDH) $\mathrm{mAb}$ (cat no. NB300-328H) were purchased from Novus Biologicals (Littleton, CO, USA). Allophycocyanin-conjugated rat anti-mouse CCR2 mAb (cat no. LS-C127284-100) was purchased from LifeSpan BioSciences (Seattle, WA, USA). Rat anti-mouse migration inhibitory factor (MIF) mAb (cat no. MAB1978) was purchased from R\&D Systems (Minneapolis, MI, USA). Rabbit anti-mouse thrombospondin (TSP)-1 mAb (cat no. orb7127) was purchased from Biorbyt (San Francisco, CA, USA).

Cell line and mice. LLC cells, a murine non-small cell lung carcinoma cell line, were purchased from Shanghai Biotechnology Corporation (Shanghai, China). Cells were maintained in Dulbecco's modified Eagle's medium (Sigma-Aldrich, St. Louis, MO, USA) supplemented with $10 \%$ fetal calf serum (Thermo Fisher Scientific, Waltham, MA, USA). C57BL/6 mice ( $n=192)$ weighing 20-25 g were supplied by the Immunology Laboratory of Nanjing Medical University (Nanjing, China) and were kept in our animal facility under specific pathogen-free conditions. All animal experiments were approved by the Guideline for the Care and Use of Laboratory Animals on the Chinese Medical Academy and the Nanjing Medical University Care Committee. Animals were kept in groups of 5 and fed regular lab chow and water ad libitum. A 12-h light/dark cycle was maintained.

Cell culture and tumor implantation model. LLC cells were grown in RPMI-1640 (Thermo Fisher Scientific) culture medium containing $10 \%$ fetal bovine serum, $2 \mathrm{mM}$ L-glutamine, 2 mM sodium pyrovate, 20 mM HEPES, $1 \%$ nonessential amino acid, $100 \mu \mathrm{g} / \mathrm{ml}$ streptomycin and $100 \mathrm{U} / \mathrm{ml}$ penicillin. Cells were maintained at $37^{\circ} \mathrm{C}$ with $5 \% \mathrm{CO}_{2}$. Cells were progressively passed to larger plates and allowed to reach $\sim 90 \%$ confluence. Cells were harvested by trypsinization, washed with HBSS buffer (Life Technologies, Grand Island, NY, USA) three times and resuspended at $1.0 \times 10^{7}$ cells per $\mathrm{ml}$ in serum-free HBSS buffer. LLC cells $\left(1 \times 10^{6}\right)$ in $100 \mu$ l HBSS buffer were injected subcutaneously into 8-week-old male C57BL/6 mice $(n=144)$. Tumor growth was assessed on day 6 , $8,10,14,16$ and 18 after LLC cell injection by the measurement of two bisecting diameters in each tumor using calipers. The size of the tumor was determined by direct measurement of the tumor dimensions. The volume was calculated according to the equation: $\mathrm{V}=\left(\mathrm{LxW}^{2}\right) \times 0.5$, where $\mathrm{V}=$ volume, $\mathrm{L}=$ length and $\mathrm{W}=$ width (22). On day 14 after tumor implantation, the mice were anaesthetized using 1.2\%, $0.2 \mathrm{ml} / 10 \mathrm{mg}$ 2-Tribro moethanol (Sigma-Aldrich) and sacrificed by dislocation of the cervical spine, and the tumor tissues were dissected and weighed.

Macroscopic assessments of cervical lymph node metastasis. The mice were sacrificed on day 21 after the implantation of LLC cells, and cervical tissues surrounding tumor masses were excised en bloc. The nearby cervical lymph nodes were removed and their weights were measured immediately.

Flow cytometric analysis of CD34-, CCR2-and F4/80-positive cells. Tumor tissues dissected from C57BL/6 mice $(n=48)$ were minced with scissors, and were homogenized in RPMI-1640 medium. Cell suspensions were then passed over a nylon filter with a $100-\mu \mathrm{m}$ pore size. The resultant cells were further stained with rat anti-mouse CD34 mAb followed by staining with PE-conjugated swine anti-rat IgG mAb. In an assay to detect $\mathrm{CCR} 2^{+} / \mathrm{F} 4 / 80^{+}$cells, cells were stained with PE-conjugated rat anti-mouse F4/80 $\mathrm{mAb}$ and allophycocyanin-conjugated rat anti-mouse CCR $2 \mathrm{mAb}$. Fluorescence intensities were determined using a FACS Calibur flow cytometer (Becton-Dickinson, Franklin Lakes, NJ, USA), together with samples stained with non-immunized swine IgG (cat. no. DAGIC1433; Creative Diagnostics, Shirley, NY, USA) or rat IgG (cat. no. DAGIC1336; Creative Diagnostics) as an isotype control.

Reverse transcription-quantitative polymerase chain reaction $(R T-q P C R)$. Total RNAs were extracted from LLC cells from mice $(n=48)$ with the use of the RNeasy Mini kit (Qiagen, Tokyo, Japan). The resultant RNA preparations were further treated with ribonuclease-free deoxyribonuclease (DNase) I (Life Technologies Inc., Gaithersburg, MD, USA) to remove genomic DNA. In total, $2 \mu \mathrm{g}$ total RNA was reverse transcribed at $42^{\circ} \mathrm{C}$ for $1 \mathrm{~h}$ in $20 \mu \mathrm{l}$ of reaction mixture containing mouse Moloney leukemia virus reverse transcriptase and hexanucleotide random primers (Qiagen). The PCR solution contained $2 \mu \mathrm{l}$ cDNA, the specific primer set $(0.2 \mu \mathrm{M}$ final concentration), and 12.5 $\mu \mathrm{l}$ SYBR Premix Ex Taq (SYBR Premix Ex Taq Perfect Real Time PCR Kit, Takara, Bio, Inc., Shiga, Japan) in a final volume of $25 \mu$ l. Quantitative PCR was performed on iCycler iQ Multi-Color Real Time PCR Detection system (170-8740, Bio-Rad, Hercules, CA, USA). PCR parameters were as follows: Initial denaturation at $95^{\circ} \mathrm{C}$ for $1 \mathrm{~min}$, followed by 40 circles of $95^{\circ} \mathrm{C}$ for $5 \mathrm{sec}$, and $60^{\circ} \mathrm{C}$ for $30 \mathrm{sec}$. The relative gene expression levels were calculated using the $2^{-\Delta \Delta \mathrm{Cq}}$ method, where $\mathrm{Cq}$ represents the threshold cycle, and GAPDH was used as a reference gene. The primers sequences are shown in Table I.All primers used were purchased from Genescript (Nanjing, China) 
Table I. Sequences of the primers used for reverse transcription-quantitative polymerase chain reaction.

\begin{tabular}{|c|c|c|c|c|}
\hline Primer & Sequence $\left(5^{\prime} \rightarrow 3^{\prime}\right)$ & $\begin{array}{l}\text { Product } \\
\text { Size (bp) }\end{array}$ & $\begin{array}{c}\text { Annealing } \\
\text { Temperature }\left({ }^{\circ} \mathrm{C}\right)\end{array}$ & $\begin{array}{l}\text { PCR } \\
\text { cycles }\end{array}$ \\
\hline \multirow[t]{2}{*}{$M I F$} & F: CCATGCCTATGTTCATCGTG & & & \\
\hline & R: AGGCCACACAGCAGCTTACT & 250 & 57 & 40 \\
\hline \multirow[t]{2}{*}{$V E G F$} & F: CTGCTGTACCTCCACCATGCCAAGT & & & \\
\hline & R: CTGCAAGTACGTTCGTTTAACTCA & 254 & 57 & 40 \\
\hline \multirow[t]{2}{*}{$M M P-2$} & F: GAGTTGGCAGTGCAATACCT & & & \\
\hline & R: GCCATCCTTCTCAAAGTTGT & 333 & 57 & 40 \\
\hline \multirow[t]{2}{*}{$M M P-9$} & F: AGTTTGGTGTCGCGGAGCAC & & & \\
\hline & R: TACATGAGCGCTTCCGGCAC & 380 & 57 & 40 \\
\hline \multirow[t]{2}{*}{$T N F-\alpha$} & F: CAGCCTCTTCTCATTCCTGCTTGTG & & & \\
\hline & R: CTGGAAGACTCCTCCCAGGTATAT & 256 & 57 & 40 \\
\hline \multirow[t]{2}{*}{$T S P-1$} & F: ACCAAAGCCTGCAAGAAAGA & & & \\
\hline & R: ATGCCATTTCCACTGTAGCC & 156 & 57 & 40 \\
\hline \multirow[t]{2}{*}{$G A P D H$} & F: ACCACAGTCCATGCCATCAC & & & \\
\hline & R: TCCACCACCCTGTTGCTGTA & 452 & 57 & 40 \\
\hline
\end{tabular}

Western blot analysis. Cell lysates from dissected tumor tissue ( $\mathrm{n}=48$ mice) were prepared 14 days after injection. Briefly, protein samples were dissolved in Laemmli buffer (Bio-Rad Laboratories, Hercules, CA, USA), boiled for 5-10 min, and centrifuged for $2 \mathrm{~min}$ at $10,000 \mathrm{x} \mathrm{g}$ to remove insoluble materials. In total, $30 \mu \mathrm{g}$ of protein per lane were separated by SDS/PAGE (12\%, Bio-Rad Laboratories) and transferred onto Immobilon-P membranes (Millipore, Bedford, MA). The membranes were blocked with phosphate-buffered saline (Thermo Fisher Scientific), containing 5\% non-fat dry milk, for non-specific binding for $1 \mathrm{~h}$ at room temperature. The blocked membranes were subsequently probed overnight at $4^{\circ} \mathrm{C}$ overnight with rat anti mouse MIF or VEGF antibodies (1:250) or rabbit anti-mouse MMP2, MMP-9, TNF- $\alpha$ or TSP-1 antibodies (1:200) respectively and mouse anti-mouse GAPDH. Membranes were subsequently washed three times for $15 \mathrm{~min}$ with phosphate-buffered saline containing Tween-20. Subsequently, the membranes were incubated with secondary horseradish peroxidase-conjugated antibody (cat. no. 611-1302; Rockland Immunochemicals, Inc., Limerick, PA, USA), and immunoreactive bands were visualized using enhanced chemiluminescence reagent (Pierce Biotechnology, Inc., Rockford, IL, USA). Immunoreactive bands corresponding to target proteins were quantified by Image J analysis (http://rsb.info.nih.gov/ij/download.html) and normalized to those of GAPDH. Blots are representative of at least three experiments.

Wound scratch assays. In order to investigate the effects of IL-17 on LLC cell migration, wound scratch assays were performed. The assay is simple and inexpensive, and the experimental conditions can be easily modified for different purposes. In brief, cells were seeded into 6 -well plates in a density that, after $24 \mathrm{~h}$ of growth, reached $70-80 \%$ confluence as a monolayer. The monolayer was gently, slowly and perpendicularly scratched with a new $1 \mathrm{ml}$ pipette tip across the center of the well. The resulting gap distance therefore equals to the outer diameter of the end of the tip. After being scratched, the wells were gently washed twice with HBSS medium (Thermo Fisher Scientific) to remove the detached cells. Then the wells were replenished with fresh medium. Cells were treated with $1 \mu \mathrm{g} / \mathrm{ml}$ human recombinant IL-17 (cat. no. NBP2-35040; Novus Biologicals) in experimental wells and phosphate-buffered saline in control wells. Cells were grown for an additional $48 \mathrm{~h}$ and cells were photographed on a BX43 microscope (Oympus, Tokyo, Japan) at $0,12,24,48$ and $72 \mathrm{~h}$. The gap distance was quantitatively evaluated using Image J software. Each experimental group was repeated three times.

Determination of the rate of cell proliferation. The rate of proliferation was determined using the Cell Counting kit 8 (CCK8, Dojindo Molecular Technologies, Kumamoto, Japan). Cells $\left(5 \times 10^{3}\right.$ cells per well) were incubated in 96-well plates and maintained in complete medium $12 \mathrm{~h}$ after IL-17 stimulation. After 24, 48 and $72 \mathrm{~h}, 10 \mu \mathrm{l}$ sterile CCK8 dye was added to the cells and incubated for $4 \mathrm{~h}$ at $37^{\circ} \mathrm{C}$. Spectrometric absorbance at a wavelength of $450 \mathrm{~nm}$ was measured on an enzyme immunoassay analyzer (ELx-800; Molecular Devices, Sunnyvale, CA, USA) after $4 \mathrm{~h}$ incubation. Experiments were performed at least three times, with six replicate measurements, and data are presented as the mean optical density \pm standard deviation.

Statistical analysis. The mean \pm standard error of the mean were calculated for all parameters determined in the study. 
A

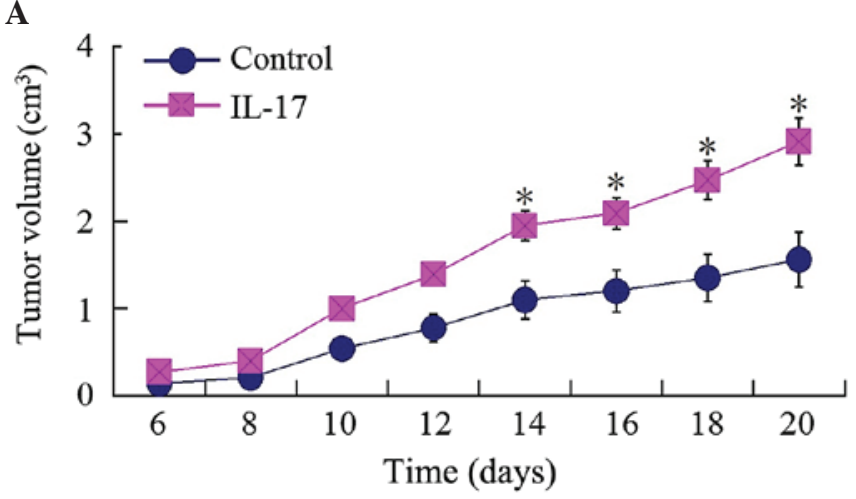

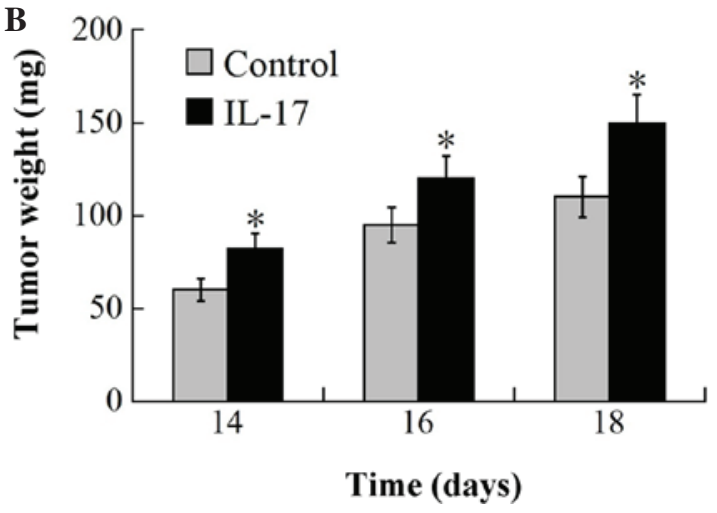

Figure 1. Growth of Lewin lung carcinoma cells subcutaneously implanted into C57BL/6 mice. A total of $10^{6}$ cells were injected into the subcutaneous tissue of male C57BL/6 mice. (A) Tumor volumes were scored on the indicated days (" $\mathrm{P}<0.05$, compared with control). (B) On days 14,16 and 18 after implantation, the tumor tissues were dissected and weighed. Results are presented as the mean \pm standard error of the mean $(\mathrm{n}=8)$. IL, interleukin.

A

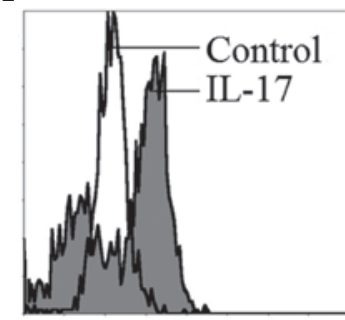

Day 14

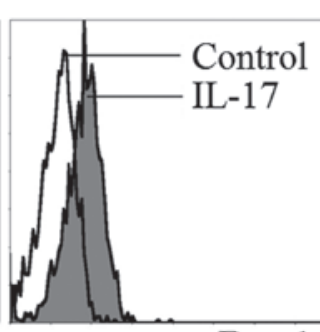

Day 16

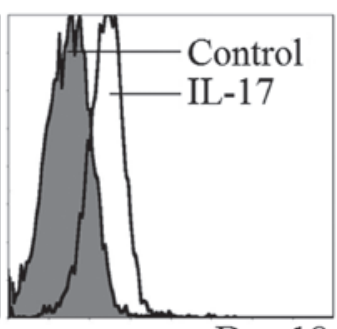

Day 18
B

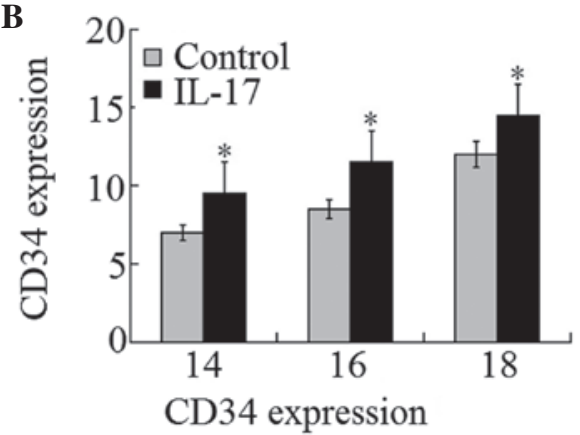

C

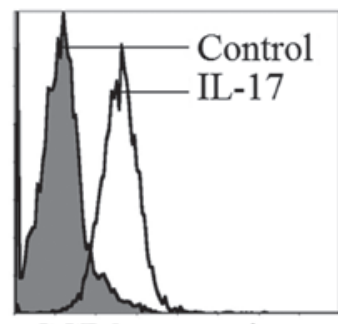

CCR2 expression

D

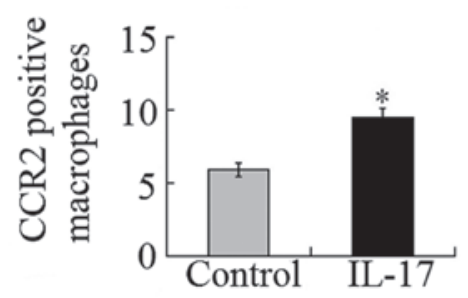

Figure 2. CD34 and CCR2 expression in F4/80-positive macrophages in implanted tumor masses analyzed by flow cytometry. At day 14 , 16 and 18 after implantation, cells were obtained from the implanted tumor masses by dissection. (A) Cells were homogenized, stained with CD34 antibodies and examined by flow cytometry. (B) Quantification of results. A significantly increased proportion of CD34 in the IL-17 group compared with control. (C) Cells were stained with CCR2 antibodies and analyzed by flow cytometry. (D) CCR2-positive macrophages were increased in the IL-17 group compared with control. ( $\mathrm{P}<0.05$, compared with control). IL, interleukin.

Data were analyzed statistically using one-way analysis of variance, or two-tailed Student's t-test. SPSS 18.0 software (IBM SPSS, Armonk, NY, USA). P $<0.05$ was considered to indicate a statistically significant difference.

\section{Results}

IL-17 significantly promotes in vivo tumor growth and angiogenesis. It was hypothesized that IL-17 promotes tumor growth and angiogenesis of lung cancer subcutaneously implanted into C57/B6 mice. To examine this hypothesis, LLC cells were grafted subcutaneously into recombinant IL-17 protein injected groups and control groups, and the development of solid tumors around the injection sites was analyzed. Tumors in IL-17-injected groups were significantly increased in size compared with those in control groups 10 days following

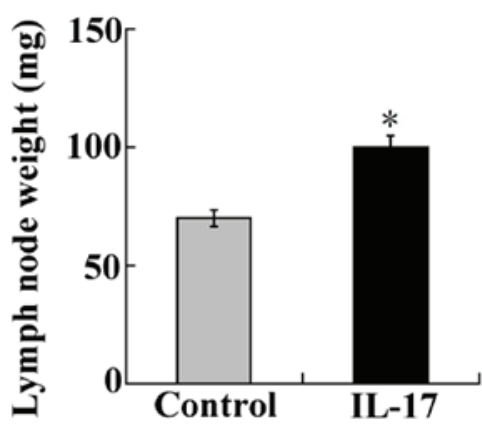

Figure 3. Enhanced tumor metastasis in IL-17 groups. A total of $10^{6}$ cells were subcutaneously injected into male IL-17 groups and control groups of C57BL/6 mice. On the indicated days after implantation, the mice were sacrificed, and the removed cervical lymph nodes surrounding implanted tumor masses were weighed. Results are presented as the mean \pm standard error of the mean $\left(\mathrm{n}=10 ;{ }^{*} \mathrm{P}<0.05\right.$, compared with control). IL, interleukin. 

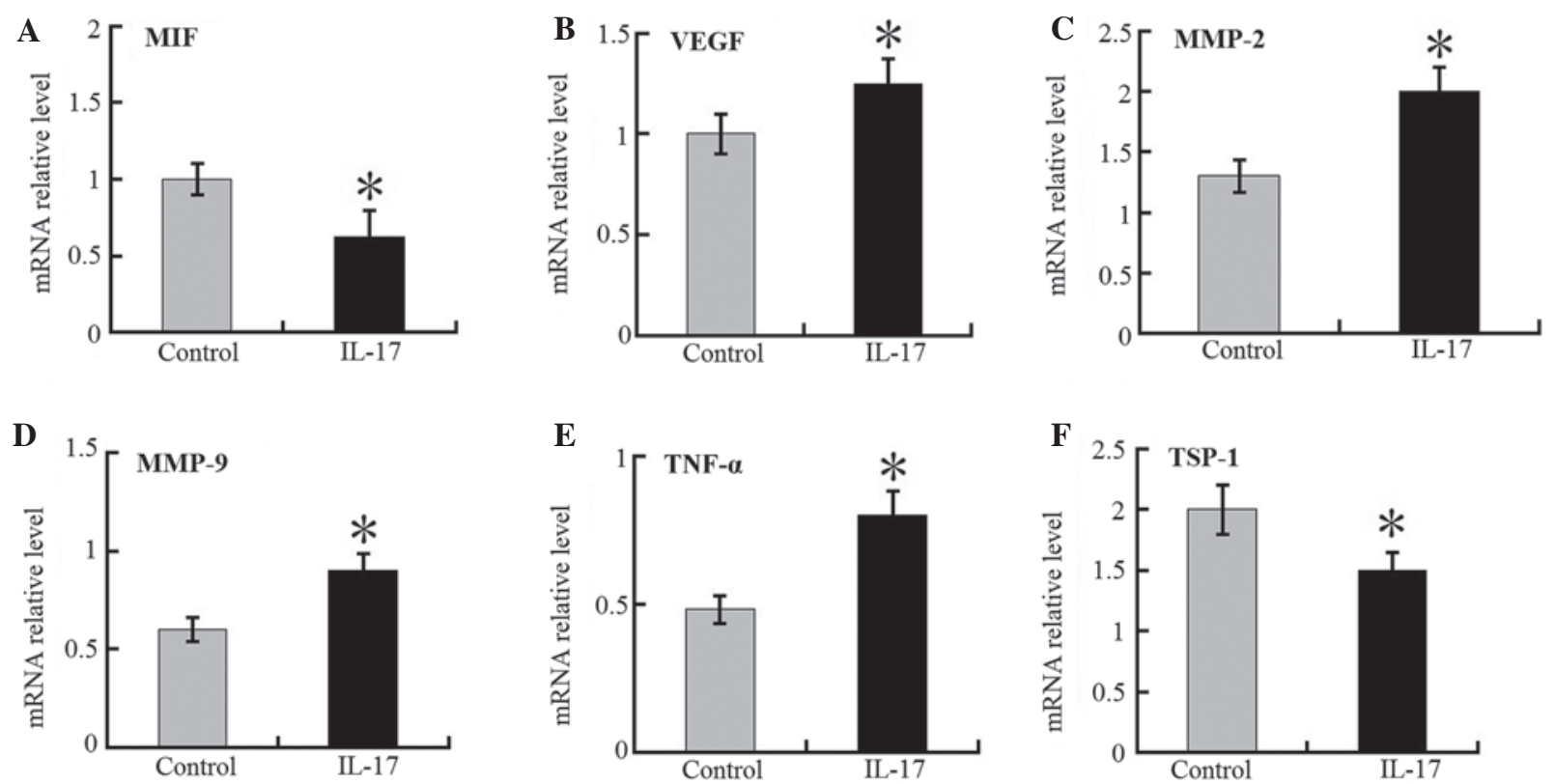

Figure 4. RT-qPCR detection of relative intra-tumor target gene expression in IL-17 groups and control mice. mRNA ratios of (A) MIF, (B) VEGF, (C) MMP-2, (D) MMP-9, (E) TNF- $\alpha$ and (F) TSP-1 to glyceraldehyde 3-phosphate dehydrogenase in tumor masses of IL-17 and control groups were determined. Each value represents the mean \pm standard error of the mean $(n=5-8) .{ }^{*} \mathrm{P}<0.05$ compared with control mice. RT-qPCR, reverse transcription-quantitative polymerase chain reaction; IL, interleukin; MIF, migration inhibitory factor; VEGF, vascular endothelial growth factor; MMP, matrix metalloproteinase; TNF, tumor necrosis factor; TSP, thrombospondin.

implantation. On day 14 after implantation, the tumor masses in IL-17 injected groups were increased to $\sim 1.5$ fold of that in control mice (Fig. 1A and B). Flow cytometry examination of xenografts revealed that the vascularization of tumor tissues was markedly increased by intraperitoneal injection of IL-17. CD34 expression of vascular endothelial cells was 20,18 and $15 \%$ higher in tumors grafted in IL-17 injected groups than those grafted in control groups at day 14, 16 and 18 after implantation, respectively (Fig. 2A and B).

IL-17 enhances CCR2-positive macrophage infiltration in tumor masses. It was reported that F4/80-positive macrophages infiltrated tumor masses and that they were associated with tumor angiogenesis (26). CCR2-positive macrophages were considered to have positive effects on tumor angiogenesis by inducing tumor cell secretion of VEGF and bFGF (27). In the present study, CCR2 expression was detected in F4/80positive macrophages that had infiltrated into tumor masses. It was demonstrated that CCR2-positive macrophages were markedly increased in IL-17-treated mice compared with control mice (Fig. 2C and D). These observations indicate that IL-17 treatment enhanced tumor mass infiltration of CCR2positive macrophages.

IL-17 significantly enhances tumor metastasis in IL-17-injected mice. Secondly, the effects of IL-17 in tumor metastasis were examined by dissecting and weighing cervical lymph nodes surrounding implanted tumor masses. The results showed that the weight of the cervical lymph nodes was markedly increased in IL-17-injected groups implanted with LLC cells compared with those of the nodes in control mice (Fig. 3A). The subcutaneous implantation of LLC cells in the IL-17-injected groups was shown to result in enhanced metastatic growth in the cervical lymph nodes as well as increased tumor volume at the implanted site when compared with the control group.

Angiogenetic factor expression is increased but MIF and TSP-1 expression is decreased in the tumors of IL-17 mice. The increased tumor angiogenesis resulted in an increase in the size of tumor foci in the xenografts of the IL-17 group, but not in the control group. It was demonstrated that the mRNA expression levels of the VEGF, MMP-2, MMP-9 and TNF- $\alpha$ in tumor tissues were markedly higher in the IL-17 group compared with the control mice (Fig. 4). In addition, the expression levels of MIF and TSP-1 mRNA were lower in IL-17 groups than in control mice. Western blot analysis demonstrated the same trend in the protein levels of these proteins (Fig. 5). These results suggest that IL-17 is pivotal in tumor-associated VEGF, MMP-2, MMP-9 and TNF- $\alpha$ production, and accompanying angiogenesis.

IL-17 stimulation increases migration in a wound scratch assay. In order to further delineate the effects of IL-17 on the biologic function of LLCs, the role of IL-17 was examined in cell migration. LLCs efficiently seal linear scratch wounds after $48 \mathrm{~h}$ culture, and this migratory process was increased following IL-17 supplementation in the culture medium. Cells migrated into the wounded area, which was markedly increased after $24 \mathrm{~h}$ in the IL-17 stimulating group (Fig. 6A). This data indicated that an increase in the migration of LLCs after IL-17 stimulation was responsible for the attenuated wound healing response.

Effects on LLC proliferation. The effect of IL-17 of LLC proliferation was also investigated. Following stimulation with 


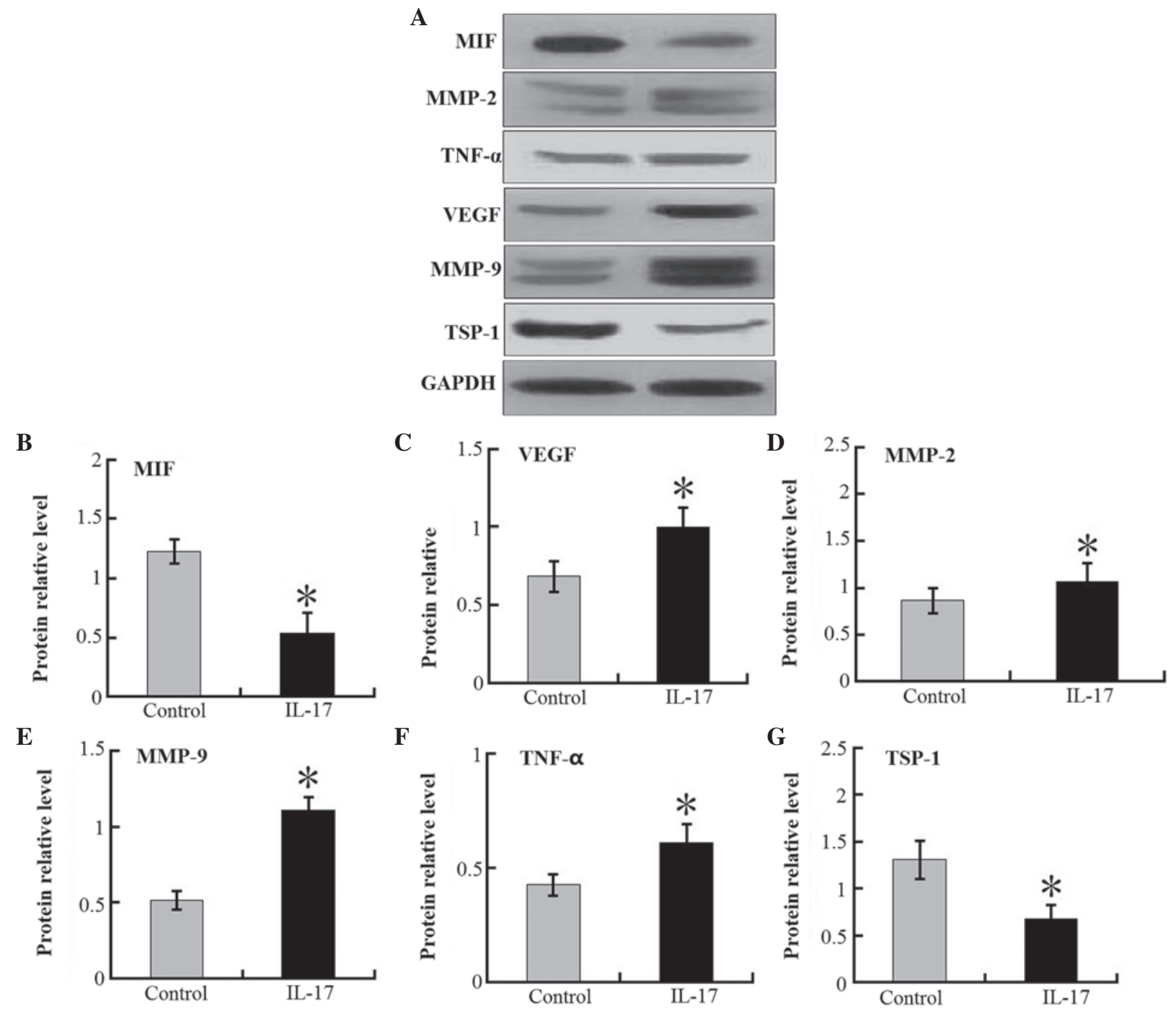

Figure 5. Western blot analysis of relative intra-tumor target protein expression in IL-17 groups and control mice. (A) Representative results of western blotting from three independent experiments. Protein ratios of (B) MIF, (C) VEGF, (D) MMP-2, (E) MMP-9, (F) TNF- $\alpha$ and (G) TSP-1 against glyceraldehyde-3-phosphate dehydrogenase in tumor masses of IL-17 and control groups were determined. Each value represents the mean \pm standard error of the mean ( $\mathrm{n}=5-8)$. "P<0.05; compared with control mice. IL, interleukin; MIF, migration inhibitory factor; VEGF, vascular endothelial growth factor; MMP, matrix metalloproteinase; TNF, tumor necrosis factor; TSP, thrombospondin; GAPDH, glyceraldehyde 3-phosphate dehydrogenase.

IL-17, LLC proliferation was determined by an MTT assay. IL-17 was not identified to increase cell proliferation, as determined by an MTT assay performed with cells up to $24 \mathrm{~h}$ after stimulation with IL-17 (Fig. 6B).

\section{Discussion}

IL-17 has recently been described as a pro-inflammatory cytokine predominantly secreted by activated $\mathrm{T}$ lymphocytes, such as Th17 cells (28), which is capable of promoting angiogenesis $(29,30)$. A recent study by Reppert et al (31) addressed the expression of Th17 markers in NSCLC. Induction of IL-17A mRNA expression was identified in lung samples derived from patients affected by lung adenocarcinoma as compared with controls, which suggested local induction of Th17 responses in the lung in NSCLC. Additional studies addressed the functional role of Th17 cells in lung cancer (32). These experiments suggested that the key cytokine IL-17 produced by lung $\mathrm{CD} 4^{+}$Th17 cells is important in experimental NSCLC. In the present study, a pivotal role and novel mechanism for IL-17 in facilitating LLC tumor growth was observed by measuring the tumor volume in vivo. IL-17 was also observed to increase the expression of VEGF, MMP-2, MMP-9 and TNF- $\alpha$ in LLCs in vivo. This indicates that LLC tumor growth was correlated with IL-17 protein expression, suggesting a possible novel biological function of IL-17 protein in tumors. This suggests that a possible therapeutic approach for lung cancer may be to target IL-17.

IL-17A has been found to favor development of tumors in certain tumor models $(33,34)$. In fact, it has previously been reported that IL-17A boosts tumor development by inducing a tumor promoting microenvironment $(33,35)$. However, it has not been investigated whether IL-17 promotes lymphatic metastasis. A previous study reported that nodal micrometastases were found in up to $36 \%$ of resected lungs from the patients with peripheral NSCLC, and the presence of metastases to the lymph nodes significantly reduces patient survival rates (36-38). Thus, the development of a strategy to suppress 


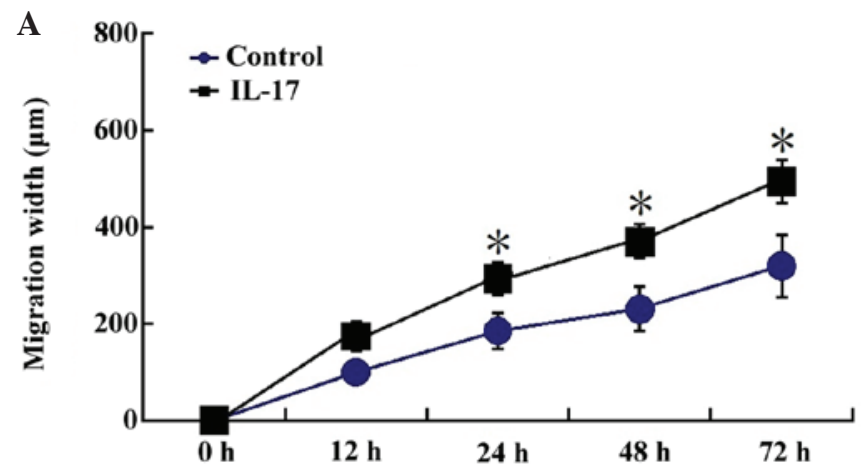

B

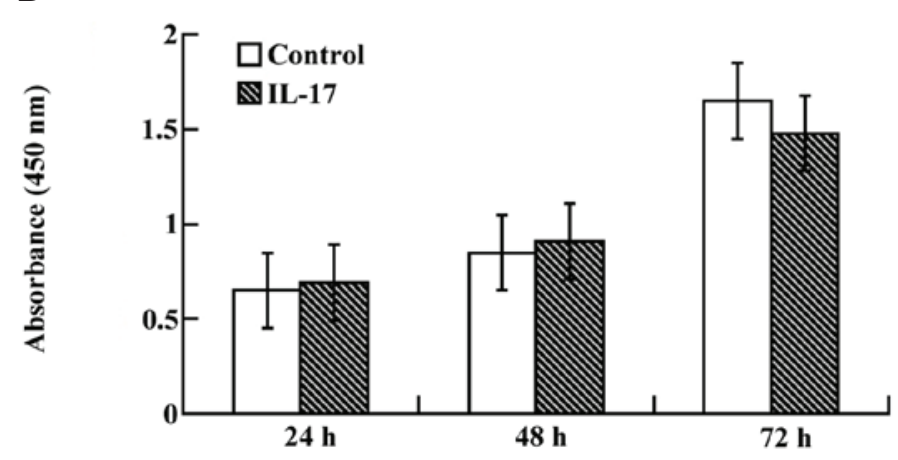

Figure 6. Wound scratch assays and cell proliferation assays to detect the effects of IL-17 on LLC cell migration and proliferation in vitro. (A) The LLC cell migration was determined. (B) Optical density values of LLC cell proliferation were determined by an enzyme-linked immunosorbent assay. Each value represents the mean \pm standard error of the mean $(n=3)$. ${ }^{*} \mathrm{P}<0.05$ compared with control. IL, interleukin; LLC, Lewis lung carcinoma.

lymphatic metastasis is critical in the treatment of patients with lung cancer patients. In the present study, implanted tumor volume and the number of cervical lymph nodes surrounding tumor masses were measured. The results showed that cervical lymph nodes surrounding tumor masses in the IL-17 group were markedly higher in weight than those in control mice. Notably, tumor volume in the groups treated with IL-17 was increased compared with those in control mice. These findings confirm that IL-17 is crucial in promoting the metastasis of implanted LLC tumor cells in vivo and concomitantly suggest that they also induce the proliferation of tumor cells.

Several lines of evidence indicate that CCR2-positive macrophages have the ability to promote secretion of angiogenic factors, resulting in tumor growth $(39,40)$. It was assumed that IL-17 may promote tumor growth by inducing CCR2-positive macrophage recruitment. Consistent with this hypothesis, intraperitoneal injection of IL-17 enhanced CCR2-positive macrophage infiltration into tumors as detected by flow cytometry. Furthermore, the IL-17/IL-17R interactions also have profound effects on the macrophage infiltration, a rich source of angiogenic factors, such as VEGF, MMP-2, MMP-9 and TNF- $\alpha$ they were all enhanced, while the expression of anti-angiogenic factor, TSP-1, was reduced in IL-17 groups. Furthermore, MIF, an inhibitor for macrophage infiltration, mRNA and protein expression was analyzed in tumor masses. RT-qPCR and western blot analysis demonstrated that MIF mRNA and protein expression levels were lower in IL-17 groups than in control groups. These observations indicate that the IL-17/IL-17R axis is crucial to tumor growth by promoting macrophage infiltration and inducing expression of VEGF, MMP-2, MMP-9 and TNF- $\alpha$ in CCR2-expressing macrophages.
A previous study revealed that IL-17 may prompt cell migration and proliferation (41). In the present study, the effects of IL-17 on LLC cell migration and cell proliferation were observed in vitro by wound scratch and CCK-8 assays, respectively. Results showed that LLC migration and proliferation were promoted by IL-17 stimulation. This suggests that IL-17 exhibits a critical role in tumor growth by multiple pathways, including promotion of angiogenesis factors expression, tumor cell migration, tumor cell proliferation and CCR2-positive macrophage infiltration into tumor masses. The exact mechanism of IL-17 in lung tumor pathogenesis remains to be elucidated, however, the preliminary results from the present study suggested that IL-17 can be used as an effective intervention target against tumor growth.

In particular, recent observations highlight a functional role of IL-17 in lung tumor progression. Targeting of cytokine-dependent molecular signaling events in tumor cells is likely to lead to innovative tailored immunotherapies for patients with lung cancer. In the present study, it was also identified that IL-17 is critically involved in LLC-implanted tumor growth, tumor metastasis and tumor angiogenesis. Furthermore, the levels of VEGF, MMP-2,MMP-9 and TNF- $\alpha$, key pro-angiogenesis factors, were increased compared with that in the control mice. Furthermore, levels of MIF and TSP-1 were decreased compared with that in the control mice. These findings suggest that IL-17 enhances cancer growth via multiple pathways. Thus, targeting IL-17 is likely to have beneficial clinical effects not only by inhibiting inflammation and tumor blood vessel formation but also by inhibiting CCR2-positive macrophage infiltration and tumor-promoting angiogenesis pathways. 


\section{Acknowledgements}

This study was supported by the Suzhou Natural Science Foundation.

\section{References}

1. Machtay M and Jeremic B: Complex and controversial issues in locally advanced non-small cell lung carcinoma. Semin Surg Oncol 21: 128-137, 2003.

2. Stanley K and Stjernswärd J: Lung cancer-a worldwide health problem. Chest 96 (Suppl 1): S1-S5, 1989.

3. Thatcher N: New perspectives in lung cancer. 4. Haematopoietic growth factors and lung cancer treatment. Thorax 47: 119-126, 1992.

4. Weynants P, Marchandise FX and Sibille Y: Pulmonary perspective: Immunology in diagnosis and treatment of lung cancer. Eur Respir J 10: 1703-1719, 1997.

5. Yao Z, Fanslow WC, Seldin MF, Rousseau AM, Painter SL, Comeau MR, Cohen JI and Spriggs MK: Herpes virus Saimiri encodes a new cytokine, IL-17, which binds to a novel cytokine receptor. Immunity 3: 811-821, 1995.

6. Starnes T, Robertson MJ, Sledge G, Kelich S, Nakshatri H, Broxmeyer HE and Hromas R: IL-17F, a novel cytokine selectively expressed in activated $\mathrm{T}$ cells and monocytes, regulates angiogenesis and endothelial cell cytokine production. J Immunol 167: 4137-4140, 2001.

7. Hymowitz SG, Filvaroff EH, Yin JP, Lee J, Cai L, Risser P, Maruoka M, Mao W, Foster J, Kelley RF, et al: IL-17s adopt a cystine knot fold: Structure and activity of a novel cytokine, IL-17F and implications for receptor binding. EMBO J 20: 5332-5341, 2001.

8. Antonysamy MA and Numasaki M: Interleukin-17 (IL-17,IL-25). In The Cytokine Handbook, 4th Ed. A. W. Thomson and M. T. Lotze, eds. Academic Press, London: 475-502, 2003.

9. Fossiez F, Djossou O, Chomarat P, Flores-Romo L, Ait-Yahia S, Maat C, Pin JJ, Garrone P, Garcia E, Saeland S, et al: T cell interleukin-17 induces stromal cells to produce proinflammatory and hematopoietic cytokines. J Exp Med 183: 2593-2603, 1996.

10. Yao Z, Painter SL, Fanslow WC, Ulrich D, Macduff BM, Spriggs MK and Armitage RJ: Human IL-17: A novel cytokine derived from T cells. J Immunol 155: 5483-5486, 1995.

11. Numasaki M, Tomioka Y, Takahashi $\mathrm{H}$ and Sasaki H: IL-17 and IL-17F modulate GM-CSF production by lung microvascular endothelial cells stimulated with IL-lbeta and/or TNF-alpha. Immunol Lett 95: 175-184, 2004.

12. Numasaki M, Takahashi H, Tomioka Y and Sasaki H: Regulatory roles of IL-17 and IL-17F in G-CSF production by lung microvascular endothelial cells stimulated with IL-1beta and/or TNF-alpha. Immunol Lett 95: 97-104, 2004.

13. Numasaki M, Lotze MT and Sasaki H: Interleukin-17 augments tumor necrosis factor-alpha-induced elaboration of proangiogenic factors from fibroblasts. Immunol Lett 93: 39-43, 2004.

14. Aarvak T, Chabaud M, Miossec P and Natvig JB: IL-17 is produced by some proinflammatory Th1/Th0 cells but not by Th2 cells. J Immunol 162: 1246-1251, 1999.

15. Yao Z, Spriggs MK, Derry JM, Strockbine L, Park LS, VandenBos T, Zappone JD, Painter SL and Armitage RJ: Molecular characterization of the human interleukin (IL)-17 receptor. Cytokine 9: 794-800, 1997

16. Kotake S, Udagawa N, Takahashi N, Matsuzaki K, Itoh K, Ishiyama S, Saito S, Inoue K, Kamatani N, Gillespie MT, et al: IL-17 in synovial fluids from patients with rheumatoid arthritis is a potent stimulator of osteoclastgenesis. J Clin Invest 103: 1345-1352, 1999.

17. Chabaud M, Lubberts E, Joosten L, van Den Berg W and Miossec P: IL-17 derived from juxta-articular bone and synovium contributes to joint degradation in rheumatoid arthritis. Arthritis Res 3: 168-177, 2001.

18. Antonysamy MA, Fanslow WC, Fu F, Li W, Qian S, Troutt AB and Thomson AW: Evidence for a role of IL-17 in organ allograft rejection: IL-17 promotes the functional differentiation of dendritic cell progenitors. J Immunol 162: 577-584, 1999.

19. Teunissen MB, Koomen CW, de Waal Malefyt R, Wierenga EA and Bos JD: Interleukin-17 and interferon-gamma synergize in the enhancement of proinflammatory cytokine production by human keratinocytes. J Invest Dermatol 111: 645-649, 1998.

20. Molet S, Hamid Q, Davoine F, Nutku E, Taha R, Pagé N, Olivenstein R, Elias J and Chakir J: IL-17 is increased in asthmatic airways and induces human bronchial fibroblasts to produce cytokines. J Allergy Clin Immunol 108: 430-438, 2001.
21. Yang B, Kang H, Fung A, Zhao H, Wang T and Ma D: The role of interleukin 17 in tumour proliferation, angiogenesis, and metastasis. Mediators Inflamm 2014:623759, 2014.

22. Murugaiyan $\mathrm{G}$ and Saha B: Protumor vs antitumor functions of IL-17. J Immunol 183: 4169-4175, 2009.

23. Miyahara Y, Odunsi K, Chen W, Peng G, Matsuzaki J and Wang RF: Generation and regulation of human CD4+ IL-17-producing T cells in ovarian cancer. Proc Natl Acad Sci USA 105: 15505-15510, 2008

24. Zhang JP, Yan J, Xu J, Pang XH, Chen MS, Li L, Wu C, Li SP and Zheng L: Increased intratumoral IL-17-producing cells correlate with poor survival in hepatocellular carcinoma patients. J Hepatol 50: 980-989, 2009.

25. Numasaki M, Watanabe M, Suzuki T, Takahashi H, Nakamura A, McAllister F, Hishinuma T, Goto J, Lotze MT, Kolls JK and Sasaki H: IL-17 enhances the net angiogenic activity and in vivo growth of human non-small cell lung cancer in SCID mice through promoting CXCR-2-dependent angiogenesis. J Immunol 175: 61776189,2005 .

26. Lin L, Chen YS, Yao YD, Chen JQ, Chen JN, Huang SY, Zeng YJ, Yao HR, Zeng SH, Fu YS and Song EW: CCL18 from tumorassociated macrophages promotes angiogenesis in breast cancer. Oncotarget 6: 34758-34773, 2015

27. Dobrzycka B, Mackowiak-Matejczyk B, Kinalski M and Terlikowski SJ: Pretreatment serum levels of bFGF and VEGF and its clinical significance in endometrial carcinoma. Gynecol Oncol 128: 454-460, 2013.

28. Park H, Li Z, Yang XO, Chang SH, Nurieva R, Wang YH, Wang Y, Hood L, Zhu Z, Tian Q and Dong C: A distinct lineage of CD4 T cells regulates tissue inflammation by producing interleukin 17 . Nat Immunol 6: 1133-1141, 2005.

29. Numasaki M, Fukushi J, Ono M, Narula SK, Zavodny PJ, Kudo T, Robbins PD, Tahara H and Lotze MT: Interleukin-17 promotes angiogenesis and tumor growth. Blood 101: 2620-2627, 2003.

30. Kato T, Furumoto H, Ogura T, Onishi Y, Irahara M, Yamano S, Kamada M and Aono T: Expression of IL-17 mRNA in ovarian cancer. Biochem Biophys Res Commun 282: 735-738, 2001.

31. Reppert S, Boross I, Koslowski M, Türeci Ö, Koch S, Lehr HA and Finotto S: A role for T-bet-mediated tumour immune surveillance in anti-IL-17A treatment of lung cancer. Nat Commun 2: 600, 2011.

32. Duan MC,Zhong XN, Liu GN and Wei JR: The Treg/Th17 paradigm in lung cancer. J Immunol Res. 2014: 730380, 2014

33. Iida T, Iwahashi M,Katsuda M,Ishida K, Nakamori M,Nakamura M, Naka T, Ojima T, Ueda K, Hayata K, et al: Tumor-infiltrating CD4+ Th17 cells produce IL-17 in tumor microenvironment and promote tumor progression in human gastric cancer. Oncol Rep 25: 1271$1277,2011$.

34. Chae WJ, Gibson TF, Zelterman D, Hao L, Henegariu O and Bothwell AL: Ablation of IL-17A abrogates progression of spontaneous intestinal tumorigenesis. Proc Natl Acad Sci USA 107: 5540-5544, 2010.

35. Charles KA, Kulbe H, Soper R, Escorcio-Correia M, Lawrence T, Schultheis A, Chakravarty P, Thompson RG, Kollias G, Smyth JF, et al: The tumor-promoting actions of TNF-alpha involve TNFR1 and IL-17 in ovarian cancer in mice and humans. J Clin Invest 119: 3011-3023, 2009.

36. Ichinose Y, Yano T, Asoh H, Yokoyama H, Yoshino I and Katsuda Y: Prognostic factors obtained by a pathologic examination in completely resected non-small-cell lung cancer. An analysis in each pathologic stage. J Thorac Cardiovasc Surg 110: 601-605, 1995.

37. van Velzen E, Snijder RJ, Brutel de la Rivière A, Elbers HJ and van den Bosch JM: Type of lymph node involvement influences survival rates in T1N1M0 non-small cell lung carcinoma. Lymph node involvement by direct extension compared with lobar and hilar node metastases. Chest 110: 1469-1473, 1996.

38. Mountain CF and Dresler CM: Regional lymph node classification for lung cancer staging. Chest 111: 1718-1723, 1997.

39. Sierra-Filardi E, Nieto C, Domínguez-Soto A, Barroso R, Sánchez-Mateos P, Puig-Kroger A, López-Bravo M, Joven J, Ardavín C, Rodríguez-Fernández JL, et al: CCL2 shapes macrophage polarization by GM-CSF and M-CSF: Identification of CCL2/CCR2dependent gene expression profile. J Immunol 192: 3858-3867, 2014.

40. Mitchem JB, Brennan DJ, Knolhoff BL, Belt BA, Zhu Y, Sanford DE, Belaygorod L, Carpenter D, Collins L, Piwnica-Worms D, et al: Targeting tumor-infiltrating macrophages decreases tumor-initiating cells, relieves immunosuppression, and improves chemotherapeutic responses. Cancer Res 73: 1128-1141, 2013.

41. Chen X, Wan J, Liu J, Xie W, Diao X, Xu J, Zhu B and Chen Z: Increased IL-17-producing cells correlate with poor survival and lymphangiogenesis in NSCLC patients. Lung Cancer 69: 348-354, 2010. 